\title{
AVALIAÇÃO DE ELEMENTOS VISUAIS ICÔNICOS QUE ATENDAM A USUÁRIOS SURDOS NAS INTERFACES DIGITAIS
}

\author{
EVALUATION OF VISUAL ICONIC ELEMENTS THAT SERVE DEAF \\ USERS IN DIGITAL INTERFACES
}

\author{
Armando Cardoso Ribas, M.Sc \\ Tarcisio Vanzin, D, Sc \\ Vania Ulbricht, D, Sc \\ Luciana Fadel, D, Sc \\ (1)UFSC \\ e-mail: mandorgr@gmail.com \\ (2) UFSC \\ e-mail:tvanzin@gmail.com \\ (3) UFSC \\ e-mail:vrulbricht@gmail.com \\ (4) UFSC \\ e-mail: liefadel@gmail.com
}

ícone, surdo, web

\begin{abstract}
Hoje a utilização de sistemas digitais é um processo que diariamente muitas pessoas utilizam, estes podem ser ouvintes, videntes, surdos, etc. A navegação desses usuários ocorre acessando hiperlinks de texto, ícones, dentre outros tipos. No entanto para os usuários surdos essa análise semântica pode ser dificultosa, pois a ausência da audição dificulta a navegação nos sistemas digitais apresentando confusão na escolha dos hiperlinks, provocada pela semelhança visual (e não semântica) entre as palavras, como também, dificuldade na compreensão na leitura. Neste momento verificou-se a importância de ícones para facilitar a navegabilidade de sistemas digitais, por isso, estudos relacionados ao desenvolvimento de ícones acessíveis para usuário surdo se fez necessário. Assim, o objetivo desse trabalho é fazer uma testagem de alguns ícones com usuários surdos.
\end{abstract}

\section{Icon, deaf, web}

Today the use of digital systems is a process that many people use daily, these can be listeners, seers, deaf, etc. Browsing these users occurs by accessing text hyperlinks, icons, and more. However for deaf users, this semantic analysis can be difficult, since the absence of hearing makes it difficult to navigate digital systems, presenting confusion in the choice of hyperlinks, caused by visual (and not semantic) similarity between words, as well as difficulty in understanding In reading. At this moment it was verified the importance of icons to facilitate the navigability of digital systems, therefore, studies related to the development of accessible icons for deaf users became necessary. Thus, the objective of this work is to do a test of some icons with deaf users. 


\section{$16^{\circ}$ \\ ERGODESIGN USIHC CINAHPA}

\section{Introdução}

Na sociedade contemporânea a tecnologia possui uma grande importância, pois vem com o intuito de potencializar ou facilitar as ações humanas, como também de melhorar a comunicação, alavancar a economia, a política, a cultura. Com isso, a tecnologia é considerada um aparato social, pois se trata de produtos, técnicas e métodos desenvolvidos cujas soluções beneficiam a sociedade (FERNANDES, 2013; FEENBERG, 2010). Em 2009 Castells (2009, pg. 16) já afirmava que:

a sociedade é que dá forma à tecnologia de acordo com as necessidades, valores e interesses das pessoas que utilizam as tecnologias [...] as tecnologias de comunicação e informação são particularmente sensíveis aos efeitos dos usos sociais da própria tecnologia. [...]

De forma análoga, Cerezo (2003) já colocava que as pessoas também devem possuir condições de avaliar os impactos das informações trazidas pelas tecnologias, as quais tendem a influenciar o seu entorno. Assim ambos os autores, deixam claro que o conhecimento gerado por estas tecnologias, está, diretamente, ligado à capacidade de organização da sociedade, captando os benefícios e excluindo informações irrelevantes. Por outro lado, a grande quantidade de usuários conectados à internet, tende a gerar um vasto número de informações, que são difundidas pelas tecnologias de informação e comunicação (TIC) essas informações são na sua grande maioria são textuais e não imagens.

Por este motivo, autores e pesquisadores, como Martins (2005,); Fernandes, (1990); Quadros, (2010) dentre outros, afirmam, que o surdo necessita de imagens para aprender, e esses autores dão ênfase o quanto é importante o uso de figuras, fotos, ícones e qualquer tipo de imagem na aprendizagem da pessoa surda. Martins(2005) complementa tais afirmações, mencionado que a falta de uma linguagem oral prejudica diretamente na compreensão da escrita $16^{\circ}$ Ergodesign - Congresso Internacional de Ergonomia e Usabilidade de Interfaces Humano Tecnológica: Produto, Informações Ambientes Construídos e Transporte

$16^{\circ}$ USIHC - Congresso Internacional de Ergonomia e Usabilidade de Interfaces Humano Computador

CINAHPA | 2017 - Congresso Internacional de Ambientes Hipermídia para Aprendizagem. sendo por este motivo, que se utiliza imagens e/ou ícones como seus substitutos.

As informações que circulam atualmente pela Web e nos computadores constituem-se de texto, imagens e sons, e destes, os mais utilizados são os textos. As imagens que são caracterizadas como linguagem não verbal, são utilizadas, em muitos casos, como decorativas ou complementares ligadas a um texto singular (fotos de eventos). Como ultimo meio de informação utilizado na Web e nas TICs, estão os sons, este meio também se enquadra como linguagem verbal. (GUIMARÃES, 2009).

Autores como Norman (1988), Nielsen (1993), Galitz $(2003,2002)$ já traziam algumas recomendações para desenvolvimento de ícones. Preece, Rogers e Sharp (2013), prosseguiram estes estudos, porem estas são informações muito subjetivas e abertas. Entretanto, a Microsoft e a Apple, possuem suas próprias diretrizes, que divergem entre si e com os autores supracitados. Fatos como este, indicam que não há um padrão de recomendação para o desenvolvimento de ícones.

\section{Cultura Surda}

A educação de surdos em sua história passou por uma evolução contínua, apesar de vários impactos marcantes. Entretanto, há períodos históricos marcados por transformação, desordem e crises, surgindo assim, oportunidades (QUADROS, 1997). Uma das crises mais marcantes e impactantes na história dos surdos foi na educação, onde muitos surdos, há mais de cem anos, "ficaram subjugados às práticas ouvintistas 1 , tendo que abandonar sua cultura, a sua identidade surda e se submeteram a uma 'etnocêntrica ouvintista', tendo que imitálos" (QUADROS, 2004). Segundo este autor isso ocorreu após o ano de 1880 em que houve o Congresso Internacional de Professores de Surdos em Milão a fim de debater e analisar a

\section{Realização:}
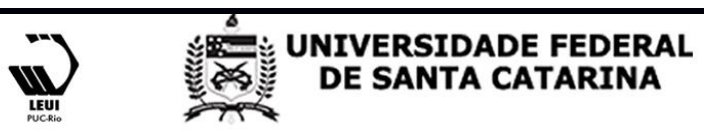


\section{$16^{\circ}$ \\ ERGODESIGN USIHC CINAHPA}

importância de três métodos rivais de ensino, a língua de sinais, a oralista2 e a mista (língua de sinais e oral). Como resultado, grande parte dos países da Europa adotou rapidamente o método oralista nas escolas para surdos, proibindo oficialmente a língua de sinais. Começando assim, uma batalha do povo surdo para defender o direito linguístico cultural (QUADROS, 2004).

A cultura surda é construída pela sociedade como uma sub-cultura, pois tem como objetivo tornar os surdos aceitos na sociedade dos ouvintes. Esta sub-cultura, não é formada por uma minoria, mas sim, a minoria da minoria (WRIGLEY, 1996). Segundo Jeff McWhinney (2001), diretor executivo da Associação Britânica de Surdos, a comunidade Surda é uma comunidade orgulhosa de si. Orgulhosa de sua cultura, orgulhosa de sua história e orgulhosa de sua linguagem. Eles (os surdos) colocam temos todos os direitos de ser orgulhosos, sobrevivendo a várias tentativas de estigmatizarão, de opressão e mesmo de eliminação.

Existem instituições que estão ajudando a cultura surda com tecnologias assistivas. $\mathrm{O}$ Conselho Deliberativo do Fundo Nacional de Desenvolvimento da Educação (FNDE) é uma delas, que desde oito de setembro de 2003, pela resolução $\mathrm{n}^{\circ} 26$, está investindo recursos financeiros para a elaboração de software para converter, traduzir textos em português para LIBRAS (LOPES, 2007).

\subsection{Como os surdos aprendem}

Como o surdo, utiliza o canal visual para ter acesso às informações de modo geral, isto é, é através da visão que ele observa o mundo, dando sentido no que vê. A Língua Brasileira De Sinais (LIBRAS) tem esse intuito, sendo totalmente

\footnotetext{
${ }^{2}$ Segundo Skliar (1998, p. 15), esse termo refere-se “ às representações dos ouvintes sobre a surdez e sobre os surdos (...) a partir do qual o surdo está obrigado a olhar-se e narrar-se como se fosse ouvinte". Com esse termo, faz-se uma analogia ao colonialismo-colonialista.
}

$16^{\circ}$ Ergodesign - Congresso Internacional de Ergonomia e Usabilidade de Interfaces Humano Tecnológica: Produto, Informações Ambientes Construídos e Transporte

$16^{\circ}$ USIHC - Congresso Internacional de Ergonomia e Usabilidade de Interfaces Humano Computador

CINAHPA | 2017 - Congresso Internacional de Ambientes Hipermídia para Aprendizagem.

visual, passa sentido e significado por uma forma que é absolutamente acessível ao surdo" (Lacerda, Santos, 2013; Moura, 2013 p. 15). Como é através da língua que as pessoas dão sentido ao mundo em que vive, a LIBRAS, como qualquer língua, possui uma estrutura gramatical própria, apresentando característica, sintaxe e semântica própria. A LIBRAS é um meio de comunicação viso-espacial que o surdo utiliza para se comunicar e trocar informações (CAMPOS, 1998).

A inteligência visual dos surdos, sem a aquisição da língua falada ou escrita, se desenvolve em contato com estímulos visuais, entretanto, o pensamento, embora possa existir sem a língua, sofre grande interferência pela falta desta. Martins e Filgueiras (2010) afirmam que existem várias barreiras na aquisição de informação pela pessoa surda por falta da língua escrita e/ou falada. Esses entraves são mais evidentes quando analisadas nas tecnologias de informação e na WEB, pois é necessário que o surdo tenha conhecimento da língua portuguesa escrita para ter acesso as informações disponibilizadas na Web. Com relação a este problema, DEBEVC; KOSEC; HOLZINGER, 2010, 2011, afirmam que por volta de $80 \%$ das pessoas surdas em âmbito mundial, possuem problemas na escrita ou leitura, o que lhes concede o grau de analfabetismo e baixa desenvoltura verbal, prejudicando seu desempenho no acesso a sites ou sistemas digitais.

\section{3 Ícone}

Os Ícones são considerados como um elemento visual da interface e possuem um grande potencial comunicacional, por este motivo ele também é diretamente responsável pela qualidade da interação e pelo desempenho do usuário.

Os ícones têm como objetivo facilitar o entendimento e a navegação diminuindo a carga cognitiva do usuário e não de prejudica-lo 


\section{$16^{\circ}$ \\ ERGODESIGN USIHC CINAHPA}

(CHENG, 2007). Eles também possuem uma característica de linguagem universal, pois segundo Passini; Strazzari; Borghi, (2008) um ícone representa significados de uma forma condensada e sintetizada. Isto é, há muitas vantagens de se utilizar imagens e ícones para a comunicação, uma vez que estes elementos visuais são processados mais rápidos que palavras. Porem estas imagens devem estar dentro do contesto e não serem aleatórias ou genéricas.

\section{1 Ícone e Surdo}

Para a confecção deste tópico, foi realizada uma revisão sistemática da literatura, utilizando as bases Scopus (www.scopus.com), periódicos da CAPES e Web of Science

(webofknowledge.com). Os trabalhos analisados trazem informações pertinentes a acessibilidade do usuário surdo e da surdez, mas nenhum trata, especificamente, do assunto ícone e surdo.

Com base nessa RSL e do levantamento realizado, não foram encontradas diretrizes, critérios ou recomendações para o desenvolvimento de ícones acessíveis ao surdo. Localizou-se artigos que tratam de assuntos como: visualização do conhecimento, aprendizagem do surdo e a diferença na aprendizagem do surdo para o aluno não surdo. Foi realizada uma busca na W3C, e da mesma forma que anteriormente, não se localizou o assunto em questão. $16^{\circ}$ Ergodesign - Congresso Internacional de Ergonomia e Usabilidade de Interfaces Humano Tecnológica: Produto, Informações Ambientes Construídos e Transporte

$16^{\circ}$ USIHC - Congresso Internacional de Ergonomia e Usabilidade de Interfaces Humano Computador

CINAHPA | 2017 - Congresso Internacional de Ambientes Hipermídia para Aprendizagem.

\section{Pesquisa de Campo}

Através da Revisão Sistemática de Literatura (RSL) e do levantamento bibliográfico foram identificadas as características dos surdos, como acontece sua aprendizagem e sua cultura.

Pesquisou-se também, como estas pessoas fazem a leitura e interpretação de ícones e imagens. Para inter-relacionar esses dados com foco na inclusão e no aprendizado do surdo, fez-se necessário duas pesquisas de campo.

A pesquisa de campo, segundo Marconi e Lakatos (1996) é uma pesquisa onde o pesquisador vai até a população pesquisada buscar informações referente sua pesquisa, exigindo do pesquisador encontros diretos. Necessitando coletar e analisar os dados sempre embasado teoricamente.

Apesar dessa pesquisa não ter cunho quantitativo, a primeira pesquisa de campo (já realizada) teve como indicador o número de pessoas surdas que responderam corretamente a interpretação dos ícones selecionados, utilizados em softwares redator de texto (Word) e editores de slides (PowerPoint). A escolha desses dois softwares deu-se em virtude de serem os mais utilizados por estes usuários (conforme entrevista realizado na Universidade Municipal de São Jose nos meses de maio e junho de 2015, com sete usuários finais e um interprete de libras).

O universo desta pesquisa são os surdos. A amostra, utilizada, foi do tipo intencional determinada com base nos critérios de inclusão e exclusão. Como critério de inclusão utilizou-se: pessoas surdas e deficientes auditivas que utilizam o computador e/ou internet, com idade igual ou superior a dezoito anos e que aceitaram participar voluntariamente da pesquisa. De forma análoga, colocou-se como critério de exclusão, possuir outras deficiências, não utilizar o computador, serem menores de 18 anos. Nestas condições 13 sujeitos participaram da pesquisa. 


\section{$16^{\circ}$ \\ ERGODESIGN USIHC CINAHPA}

Para a entrevista foi elaborado um roteiro com 26 questões, divididas em grupos que abordam: perfil do usuário - da $1^{\text {a }}$ a $9^{\mathrm{a}}$ questão onde se identificou sua formação, uso do computador e da internet e quais editores de textos e slides mais utilizam; compreensibilidade - da questão 2.1 a 2.20 , verificou-se o conceito de ícone e sua compreensão de ícones.

A pesquisa foi aplicada em um grupo de 13 de surdos. Ao final das entrevistas semiestruturada junto à amostra da população, os dados foram tabulados e tratados. A partir desta análise foram geradas as identificações sobre a compreensão dos ícones. Para este fim foram escolhidos os ícones que usualmente são utilizados no softwares Word e Power Point. Estes ícones, em número de 15, estão dispostos na tabela 2.

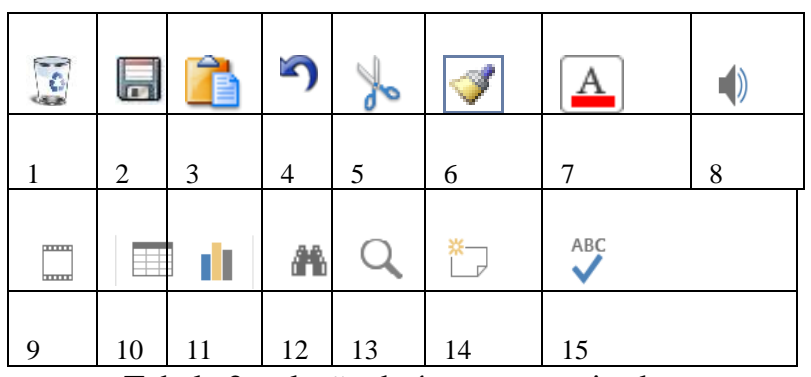

Tabela 2: relação de ícones pesquisados

\section{Resultados da pesquisa estruturada}

Com essa pesquisa pode-se verificar que os ícones 1, 2, 5, 7 e 9 da tabela 9 é que passaram maior significado de sua funcionalidade para $o$ público pesquisado, pois mais da metade dos entrevistados conseguiram identificar a intenção da funcionalidade de tais ícones.

Sobre o ícone salvar (tabela 2 - figura 2), somente $16 \%$ (2) dos entrevistados não conseguiram entender o significado deste ícone, Já no gráfico 2 é possível verificar que $84 \%$ (11) dos entrevistados identificaram que o ícone $16^{\circ}$ Ergodesign - Congresso Internacional de Ergonomia e Usabilidade de Interfaces Humano Tecnológica: Produto, Informações Ambientes Construídos e Transporte

$16^{\circ}$ USIHC - Congresso Internacional de Ergonomia e Usabilidade de Interfaces Humano Computador

CINAHPA | 2017 - Congresso Internacional de Ambientes Hipermídia para Aprendizagem.

de tesoura tem a funcionalidade de recortar alguma coisa, mesmo assim 16\% (2) dos usuários pesquisados não identificaram sua funcionalidade.

No ícone que representa a funcionalidade de alterar cor da fonte do texto (7), houve $92 \%$ (12) dos usuários que conseguiram identificar tal funcionalidade.

No no ícone inserir vídeo somente $85 \%$ (11) dos usuários entrevistados conseguiram identificar qual é a finalidade que o ícone, imagem $9 \mathrm{da}$ tabela 9 , passa para o usuário final.

Os ícones que não houve um entendimento de suas finalidades não são considerados ícones metafóricos, pois segundo Santaella(2012), devem representar um objeto com qualidade, que deve apresentar um grau de semelhança com o artefato real, passando entendimento de suas funcionalidades.

Pode-se observar que no gráfico 6 somente 54\% (7) dos entrevistados souberam identificar a funcionalidade desse ícone (escrever nota), $31 \%$ (4) identificaram o sentido de escrever nota, $8 \%$ (1) consideraram que esse ícone passa o entendimento da funcionalidade anexar arquivo e 7\% ( 1 ) consideraram que significa recortar

No ícone 7 da tabela 9, pode-se identificar que somente $31 \%$ (4) identificaram sua funcionalidade, enquanto 69\% (9) dos entrevistados não identificaram o significado desse ícone que é desfazer. Já o ícone de copiar formato não foi entendido por $92 \%$ (12) dos entrevistados.

O ícone número 8 da tabela 2 deveria passar a significação de inserir som no PowerPoint, porem somente $23 \%$ (3) dos entrevistados tiveram esse entendimento. Na imagem 10 da tabela 2 somente $44 \%$ (6) dos pesquisados não conseguiram identificar que esse ícone é utilizado para inserir tabela

O ícone 11 da tabela 2 , mostra que $8 \%$
Realização:

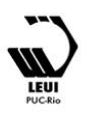




\section{$16^{\circ}$ \\ ERGODESIGN USIHC CINAHPA}

(1) dos entrevistados não identificaram qual é o seu significado, já 38\% (5) deduziram que deve ser utilizado para pintar o texto escrito com três cores distintas e 54\% (7) identificaram a significação correta.No ícone de binóculos é possível verificar que $23 \%$ (3) compreenderam que este ícone passa a ideia de localizar e $77 \%$ (10) compreendem que este ícone deve ser utilizado para zoom (aumentar texto). No ícone lupa (ícone 13 da tabela 2), somente 38\% (5) identificaram sua significação correta no Word ou PowerPoint, já os 54\% (7) dos pesquisados consideram que este passa uma informação de zoom e $8 \%$ (1) não tem ideia para que serve este ícone.

Com isso é possível verificar que muitos dos ícones utilizados nesses aplicativos não passam significação correta de suas funcionalidades para o público pesquisado, daí a necessidade do estudo proposto referente a compreensibilidade iconográfica pelos usuários surdos

\section{BIBLIOGRAFIA}

BESSA, O. F. M. A agradabilidade do espaço urbano construído da cidade de Alfenas (MG): uma abordagem ergonômica. Rio de Janeiro: PUC-Rio, 2001.

CULLEN, G. Paisagem Urbana. Lisboa: Edições 70, 1996.

\section{ABRA- "Associação Brasileira de}

Acessibilidade". Disponível em:

<http://www.acessibilidade.org.br>. Acesso em: Outubro de 2014.

BRASIL, Acessibilidade digital. Disponível em:

http://www.acessobrasil.org.br/index.php?itemid $=42$. Acesso em 06/2015)

BRASIL. Lei no 10.436, de 24 de abril de 2002. Dispõe sobre a Língua Brasileira de Sinais - $16^{\circ}$ Ergodesign - Congresso Internacional de Ergonomia e Usabilidade de Interfaces Humano Tecnológica: Produto, Informações Ambientes Construídos e Transporte

$16^{\circ}$ USIHC - Congresso Internacional de Ergonomia e Usabilidade de Interfaces Humano Computador

CINAHPA | 2017 - Congresso Internacional de Ambientes Hipermídia para Aprendizagem.

Libras e dá outras providências. Lex:

Presidência da República, Brasília. Disponível em:

<http://www.planalto.gov.br/ccivil_03/leis/2002/ 110436.htm>. Acesso em: 9 mar 2015.

BRASIL. Portaria no 3, de 7 de maio de 2007. Institucionaliza o modelo de acessibilidade em governo eletrônico - e-MAG - no âmbito do sistema de administração dos recursos de informação e informática - SISP. Lex: Diário Oficial da União, seção 1, Brasília, 8 maio 2007.

BRASIL. Ministério do Planejamento, Orçamento e Gestão. Secretaria de Logística e Tecnologia da Informação. Modelo de acessibilidade em governo eletrônico (eMAG). Brasília, 2014. 91 p.

BOTELHO, P. Segredos e silêncios na interpretação dos surdos. Belo Horizonte: Autêntica, 1998.

CASTRO, A. A. Revisão sistemática e metaanálise. São Paulo. LED-DIS/ Unifesp, 2001 Disponivel em http//:www.metodologia.org acessado em 12 de fevereiro de 2013.

CAMPOS, Márcia de Borba; SILVEIRA,Milene Selbach. Tecnologias para Educação Especial. In: Anais: IV Congresso RIBIE, Brasilia, 1998. 24 páginas.

CEREZO, J. A. L. Ciência, Técnica e Sociedade. In: IBARRA A.; OLIVÉ, L. Questiones Éticas de la Ciência y de la Tecnologia en el siglo XXI. Madri: OEI y Biblioteca Nueva, 2003.

CHARTIER, Roger, 1994 "CULTURA POPULAR": revisitando um conceito historiográfico. Disponível em: http://www.cpdoc.fgv.br/revista/arq/172.pdf. Acessado em 05 de junho de 2007.

CDPD. Benefício da prestação continuada e trabalho mudanças da lei $\mathrm{n}^{\circ} 12.470$, de 31 de agosto de 2011. Maria Aparecida Gugel.
Realização:

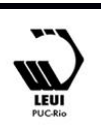




\section{$16^{\circ}$ \\ ERGODESIGN USIHC CINAHPA}

Convenção sobre os Direitos das Pessoas com Deficiência (CDPD). 2011.

CYBIS, Walter de Abreu. Abordagem ergonômica para IHC: ergonomia de interfaces humano-computador. Florianópolis: LabIUtil - Laboratório de Utilizabilidade INE/UFSC. Disponível em www.labiutil.inf.usfc.br/

FERNANDES, E. Problema linguísticos e cognitivos do surdo. Rio de Janeiro: Agir, 1990

FAJARDO, I., et al. Information structure and practice as facilitators of deaf users' navigation in textual websites. Behaviour \& Information Technology, Londres, v. 28, n. 1, p. 87-97, jan./fev. 2009.

FAJARDO, I., et al. Improving deaf users' accessibility in hypertext information retrieval: are graphical interfaces useful for them? Behaviour \& Information Technology, Manchester, v. 25, n. 6, p. 455 - 467, nov./dez. 2006.

FAJARDO, I., et al. Information structure and practice as facilitators of deaf users' navigation in textual websites. Behaviour \& Information Technology, Londres, v. 28, n. 1, p. 87-97, jan./fev. 2009.

LÉVY, Pierre. Cibercultura. São Paulo: Editora 34, 1999.

MARCONI, Marina de Andrade; LAKATOS, Eva Maria. Metodologia científica. 6. ed. São Paulo: Atlas, 2011.

MARTINS, E. Cultura surda, educação e novas tecnologias em Santa Catarina. Dissertação (Mestrado em Sociologia Politica) Universidade Federal de Santa Catarina (UFSC). Florianópolis, 2005

PREECE, J.; ROGERS, Y; SHARP, H. Design de Interação: Além da interação homemcomputador. Porto Alegre, Bookman, 2005. $16^{\circ}$ Ergodesign - Congresso Internacional de Ergonomia e Usabilidade de Interfaces Humano Tecnológica: Produto, Informações Ambientes Construídos e Transporte

$16^{\circ}$ USIHC - Congresso Internacional de Ergonomia e Usabilidade de Interfaces Humano Computador

CINAHPA | 2017 - Congresso Internacional de Ambientes Hipermídia para Aprendizagem.
QUEIROZ, J. E. R. Abordagem Híbrida para a Avaliação da Usabilidade de Interfaces com o Usuário. Projeto de Pesquisa da Universidade Federal de Campina Grande, 2006.

RAMALHO E OLIVEIRA, S. R. Leitura de imagens para a educação. 1998. 288 f. Tese (Doutorado em Comunicação e Semiótica). Pontifícia Universidade Católica de São Paulo, São Paulo.

Arte, estética do cotidiano e relações culturais. 2002. Pesquisa de Pós-Doutorado. Université des Sciences et Technologies de Lille. Lille.

ROCHA, H. V., BARANAUSKAS, M. C. C. Design e avaliação de interfaces humano- computador. Campinas, SP: NIED/UNICAMP, 2003. Disponível

em:<www.nied.unicamp.br.> Acessado em: 5 mar 2016.

SANTAELLA, L. A percepção. São Paulo: Experimento, 1993
Realização:

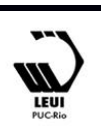

